\title{
Implementing project-based pedagogy in optical system design courses development
}

Yifan Huang, Qun Hao, Lin Li

Yifan Huang, Qun Hao, Lin Li, "Implementing project-based pedagogy in optical system design courses development," Proc. SPIE 9793, Education and Training in Optics and Photonics: ETOP 2015, 97932D (8 October 2015); doi: $10.1117 / 12.2223210$

Event: Education and Training in Optics and Photonics: ETOP 2015, 2015, Bordeaux, France 


\title{
Implementing project-based pedagogy in Optical System Design courses development
}

\author{
Yifan Huang*, Qun Hao, Lin Li \\ ,School of Opto-electronics, Beijing Institute of Technology \\ 5\# Zhongguancun south street, Beijing ,CHINA
}

\begin{abstract}
The paper describes how the pedagogy of project based learning (PBL) was integrated into the Optical System Design course at School of Opto-electronics of Beijing Institute of Technology, Beijing, China. The course teaching philosophy, implementation methodologies, examples and experiences were discussed
\end{abstract}

\section{INTRODUCTION}

China is now making great efforts to transform from a big to a powerful country in technology, so the high demands for reforming traditional education in science and engineering university are put forward. Our goal is to foster qualified engineers required by industries, but traditionally engineering education in China is detached from or lags behind the rapidly growing industry, and the connection between industries and universities is not close enough. The situation has led to the poor practical ability of the graduates when they start working. Our engineering education is facing unprecedented challenges and exciting opportunities,

In recent years project based learning-PBL, one of the most effective tools used in engineering education, has become increasingly accepted as a useful concept in China. PBL is becoming the favored pedagogical model for teaching technical courses, transforming lecture-based teaching to address more complex open-ended real-world problems.

Optical System Design is a very important course for the students at School of Optoelectronics, Beijing Institute of Technology, who plan to work in optical area. Traditionally, this course will be given by telling students the aberration principles, software application and designing methods of traditional typical optical systems. Students are required to make several design projects using optical simulating software. Since optical system designing needs a good understanding of both designing theory and engineering experience, students always found that their designs were impractical. What was worse, most of their design could not be manufactured since they did not consider the production process at all.

From 2011, an approach of project-based learning has been made in the course of "Optical System Design". The approach was motivated by the following factors: (1) to explore and develop a new engineering education mode for the students majored in optoelectronics. (2) to meet the huge local industry needs for optical engineers with strong practical solution abilities. Aiming at these objectives, multidisciplinary synthesis, teamwork and communication, hands-on and laboratory experiences, and real-world projects from industries are emphasized in the teaching process.

The paper will discuss how the philosophy of PBL was integrated into the Optical System Design course. The following section of this paper is: Section 2 is the course description. PBL implementation methodologies and examples are given in Section 3. And we conclude our work in Section 4.

*huangyifan@bit.edu.cn;

Education and Training in Optics and Photonics: ETOP 2015, edited by Eric Cormier, Laurent Sarger Proc. of SPIE Vol. 9793, 97932D · (c) 2015 SPIE, IEEE, OSA, ICO · doi: 10.1117/12.2223210 


\section{COURSE DESCRIPTION}

\subsection{Teaching philosophy}

Generally, the teaching philosophy of Optical System Design (OSD) course is to train students in the following three aspects:

- Knowledge: An excellent optical system designer must have a solid foundation of knowledge on aberration, optical design theoretical knowledge as well as mathematical optimization methods. In consideration of solving real-world open-ended problems, the integration of different disciplines into one product or system is essential, and this course is devoted to developing students these skills.

- Capability: Capability of problem solution ability is the basic requirement for the optical design engineers. At the same time, soft skills such as teamwork, communication and leadership are also very important for them.

- Scientific Literacy: Scientific Literacy is a combination of scientific cognition, scientific methods and scientific spirit. The cultivation of scientific literacy is a long-term process. In this course what are mainly emphasized are scientific attitude, scientific conscious and social responsibility when designing a system.

\subsection{Learning outcomes}

The learning outcomes for the students after completing OSD course lie in the following aspects:

- Understanding the basic theories of optical system design.

- Having the ability to analyze real-world optical system problems and make design proposal.

- Proficiency in typical methods and progress of designing typical optical systems.

- Gaining experience in optical manufacturing, alignment and testing.

- Considering and working across disciplines (optics, mechanical, electronics, computer and software, etc.) on team work.

\subsection{Administration of the course}

The OSD course was first implemented in 2011 and has been conducted for 4 years for undergraduate students majored in optoelectronics at the third year. The administration structure of OSD course is shown in figure.1. The course responsible professor has the overall responsibility for the whole course. Besides making teaching plan, a very important part of his work is to establish and maintain good contacts with industries that can provide project assignments. There will be several projects assigned for the students. In each project, there is an academic supervisor as well as an industrial supervisor from the project assigning industry. The academic supervisor is responsible for instructing students to do design and simulation, organizing the whole process, while the industrial supervisor helps the student considering manufacturing process and production cost. They are also very helpful for students' future career planning.

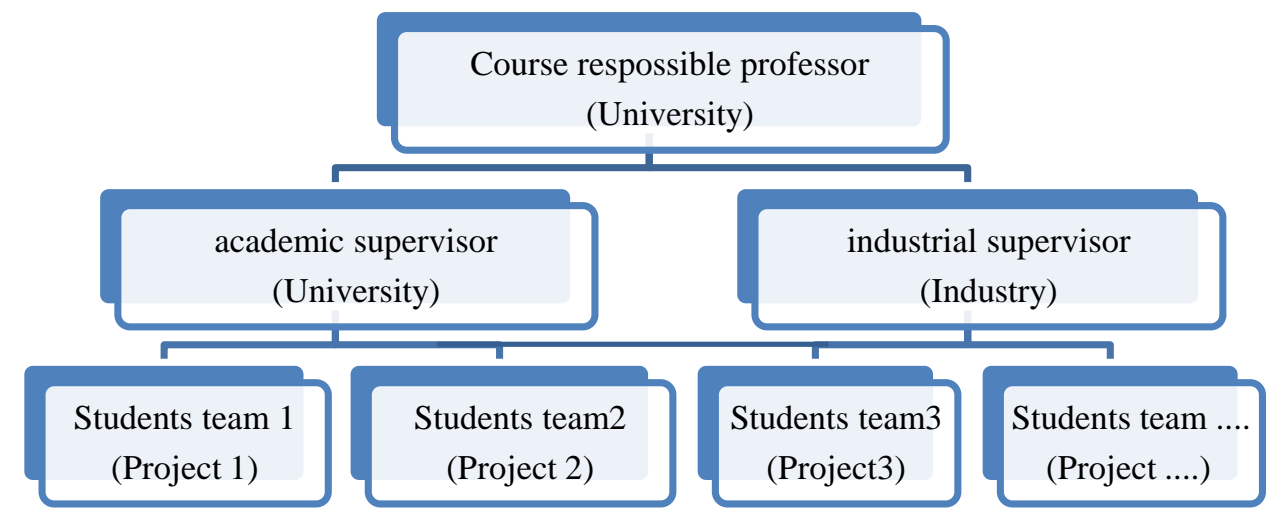

Figure 1. Administration structure 


\section{PBL IMPLEMENTATION PEDAGOGIES}

\subsection{Schedule of the course}

The OSD course is taken in spring semester, and it will last for 14 weeks, 4 hours per week. In addition, a 2-week internship at optical industries is arranged in dispersive time.

The Schedule of the course is shown in Table 1.

Table 1. Schedule of OSD course

\begin{tabular}{|l|l|l|}
\hline \multicolumn{1}{|c|}{ Week No. } & \multicolumn{1}{|c|}{ Contents } & \multicolumn{1}{c|}{ Responsible Person } \\
\hline $1^{\text {st }} 5^{\text {th }}$ & $\begin{array}{l}\text { Introduction of aberration, Optical design } \\
\text { theory, Software, Common design process }\end{array}$ & Academic Supervisor \\
\hline $6^{\text {th }-7^{\text {th }}}$ & $\begin{array}{l}\text { Introduction of manufacturing, Combination } \\
\text { of optics and mechanics, project assign }\end{array}$ & Industrial Supervisor \\
\hline $8^{\text {th }-11^{\text {th }}}$ & $\begin{array}{l}\text { Team establishing, Task decomposition, } \\
\text { System design }\end{array}$ & Academic Supervisor \\
\cline { 2 - 3 } & $\begin{array}{l}\text { 2-week internship at optical industries in } \\
\text { dispersive time }\end{array}$ & Industrial Supervisor \\
\hline $12^{\text {th }}-13^{\text {th }}$ & Revise the original design & $\begin{array}{l}\text { Academic Supervisor } \\
\text { Industrial Supervisor }\end{array}$ \\
\hline $13^{\text {th }}-14^{\text {th }}$ & Preparing the final report, presentation & $\begin{array}{l}\text { Academic Supervisor } \\
\text { Industrial Supervisor }\end{array}$ \\
\hline
\end{tabular}

Usually, we have about 30 students in our class. They can be divided into 5-6 teams. Each team will be assigned a project from the industry. All the projects come from real production or research projects. Students themselves can determine the division of labor and individual responsibility, such as overall program proposal, optical system design and optimization, structure design, report writing and presentation. The individual capability and team cooperation support the team throughout the whole process.

From Table 1, we can see the internship at industries is arranged in week 8-11, when the teams are doing system design at the same time. In dispersive time, students will go to the workshop of the industry to participate in the process of optical element manufacturing, testing and optical-mechanical alignment. In this process, students come to know the requirements from the real production. With this experience, they can revise their original design after they come back to their class.

\subsection{Example}

One of our project-based examples is that: students in a team were asked to design an industrial triplet lens system. This project was a typical opto-electronic project composed of optical, mechanics. The key issues in this project included: optical ray tracing, aberration optimization, structure design, engineering drawing, optical manufacturing and alignment.

Fundamental theoretical lectures were given to the students at the first 5 weeks. Students learned the basic definition of optical system design, and the method to use optical system design software. In the following 2 weeks, the project was assigned to the students and basic knowledge of the project was given by the industrial supervisor. According to their interests, each student in this team chose one main topic to do research work. The following weeks will be spent in an open-classroom. Every week, the team comes to the academic adviser to illustrate their discussions and progress. The advisor will give them some advice on how to do next. This situation will last for about 4 weeks when an expected original design result can be gotten. 
During these weeks, students would have a flexible timetable. They were arranged to go to industries to attend the real production process. They saw how the lens was manufactured and the how the optical mechanical structure was aligned. In this procedure, students can have the opportunity to gain the fundamental knowledge of optical components manufacture. And the students then could modify their design after the engineers in the industry led them to know the real engineering possibilities. In this procedure, make their design come true. The lens will be manufactured, and the mechanical structure will be made.

Since the triplet lens is a relative simple structure, the students can make their design come true. With the help of industries, lenses were manufactured. In order to evaluate the quality of the design, students also learned to do alignment for the optical component and mechanical structure. They used the centre scope, edge tester and interferometer in laboratory to test the system. Detailed records of the above processes were required as parts of the final reports.
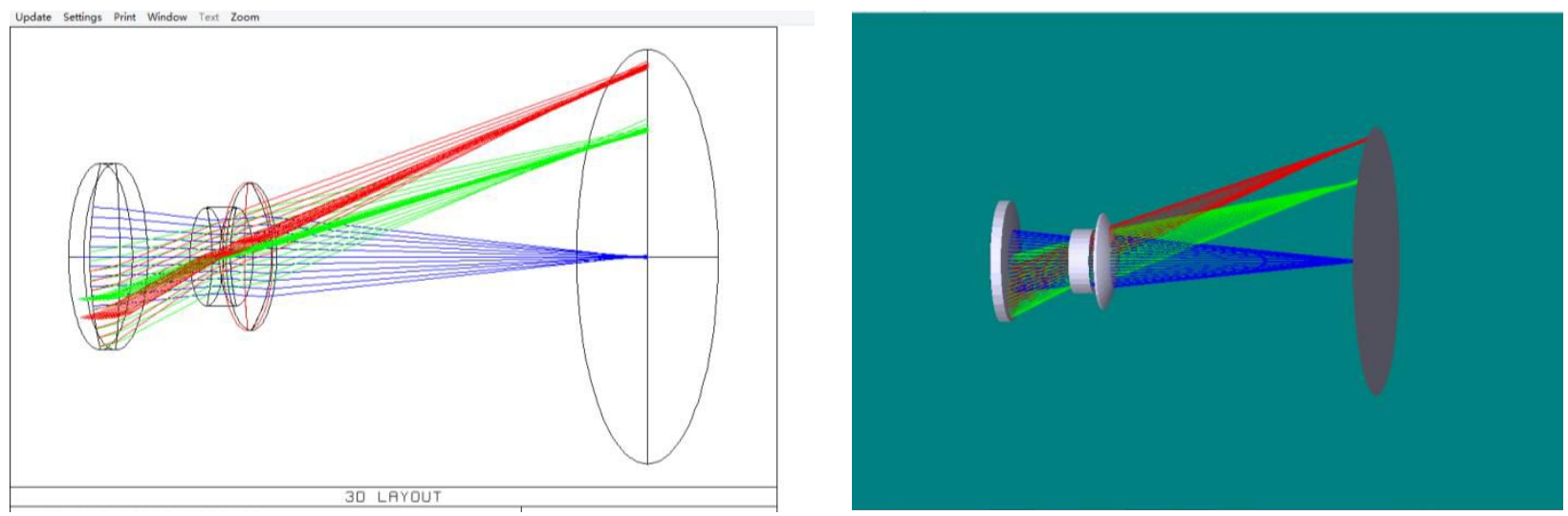

Figure 3. Design example in OSD course

\subsection{Deliverables and Evaluation}

The deliverables for OSD course include:

- Preliminary report .

- Intermediate design report.

- Final report.

- Final presentation in front of the whole class.

- Image quality records of their system.

In the final presentation, every student is expected to present his work in the project and be able to answer questions about any aspect of the project. This encourages a sense of responsibility for the project in addition to ensuring that all students engage in and benefit from the PBL learning process.

The grading for OSD course was based on individual and team performance as well as theoretical learning.

- Team evaluation: The teams are evaluated at each stage. Usually, grading for each team includes four parts, project design proposal, intermediate report, final report and presentation, image quality of the designed system.

- Individual evaluation: the mark for each student is based on their individual contribution to the project. They final grade includes three parts: theoretical examination, individual contribution and group performance.

\subsection{Student feedbacks}

Every time we finish this course, we will conduct a survey to obtain the feedbacks from students. Here are comments from some students: 
- This is a very good course, and our practical solving ability was enhanced greatly.

- The experience in industry helps me make connection between books and practice.

- I like the project based learning mode. It tells me how to think and take measure in front of a real problem.

- My hands-on skills were improved.

- The students can gain much more through practice and experiments.

- This course needs much time in order to develop our technical and soft skills. But whatever this course is perfect.

\section{CONCLUSIONS}

PBL has been found to be an effective way in engineering teaching. In the process of introducing this pedagogy to the curriculum of optical System Design course, we get a lot of positive results. But we are very clear that there is still much space left to be improved. The selection of projects, balance between guidance and self-directed active learning, task decomposition, faculty experience and teaching resources are important issues to be considered next. We will try to make PBL pedagogies more scientific and efficient. In this way, students can gain the knowledge and skills, which help them transfer smoothly from universities to industries.

\section{REFERENCES}

[1] Robert M. Bunch et al., "Rethinking optical engineering capstone design experience", Proc. SPIE, Vol. 7783, 2010.

[2] J. Burge and R. E. Parks, "Opto-mechanical engineering education at University of Arizona", Proc. SPIE, Vol. 7424, 2009.

[3] Van Derlofske, J. F., "Computer modeling of LED light pipe systems for uniform display illumination," Proc. SPIE 4445, 119-129 (2001). 